\title{
Surgery in Chronic Pancreatitis: Indication, Timing and Procedures
}

\author{
Stefan A.W. Bouwense ${ }^{a}$ Marinus A. Kempeneers ${ }^{d}$ Hjalmar C. van Santvoort ${ }^{\text {b, }}$ \\ Marja A. Boermeester ${ }^{d}$ Harry van Goor ${ }^{\mathrm{a}}$ Marc G. Besselink ${ }^{\mathrm{d}}$ \\ Dutch Pancreatitis Study Group \\ a Department of Surgery, Radboud University Medical Center, Nijmegen, The Netherlands; ${ }^{\mathrm{b}}$ Department of \\ Surgery, St. Antonius Hospital, Nieuwegein, The Netherlands; ' Department of Surgery, University Medical Center \\ Utrecht, Utrecht, The Netherlands; ${ }^{\mathrm{d}}$ Department of Surgery, Amsterdam Gastroenterology and Metabolism, \\ Amsterdam UMC, University of Amsterdam, Amsterdam, The Netherlands
}

\section{Keywords}

Chronic pancreatitis · Pain · Surgery $\cdot$ Timing of

interventions - Early treatment

\section{Abstract}

Chronic pancreatitis is a chronic inflammation of the pancreas with pain as its severest symptom and often an impaired quality of life. Surgical intervention plays an important role in the management of pain but is generally kept as a last resort when conservative measures and endoscopy have failed. However, in the last few years multiple studies suggested the superiority of (early) surgical treatment in chronic pancreatitis for multiple end points, including pain relief. In this paper we highlight the most recent high-quality evidence on surgical therapy in chronic pancreatitis and the rationale for early (surgical) intervention.

(c) 2019 The Author(s)

Published by S. Karger AG, Basel

\section{Introduction}

Chronic pancreatitis is an inflammatory disease of the pancreas characterized by fibrosis and irreversible morphological changes, with permanent loss of endocrine and exocrine function. The natural history of chronic pancreatitis patients is unpredictable, symptoms (especially pain) seem not always directly correlated with the morphological changes of the pancreas and its surrounding tissues [1].

\section{KARGER (c) 2019 The Author(s)
Published by S. Karger AG, Basel
Open access

This is an Open Access article licensed under the Creative Commons Attribution-NonCommercial-4.0 International License (CC BY-NC) (http://www.karger.com/Services/OpenAccessLicense), applicable to the online version of the article only Usage and distribution for con(n)
Pain is the most frequent and debilitating symptom, and the pattern of pain varies widely between patients, ranging from mild complaints to recurrent attacks or continuous uncontrollable pain. Additional symptoms may develop from extension of the pancreatic inflammation and fibrosis to adjacent organs and vascular structures leading to i.e. duodenal and bile duct stenosis, and progressive loss of endocrine and exocrine function resulting in diabetes and maldigestion [2]. Management of chronic pancreatitis should be in a multidisciplinary approach including radiological, endoscopic and surgical expertise combined with pain management, nutritional, endocrinological and psychological support. Still, the optimal treatment of chronic pancreatitis pain has been debated for many years, and therefore practice differs. Differences in opinions are fuelled by the lack of knowledge on the natural course and origin of pain in chronic pancreatitis, together with a lack of a clear correlation between the severity of complaints and the presence and extent of morphological abnormalities. There is a relative lack of high-quality data on the treatment of chronic pancreatitis which means that the indications for treatment, ranging from conservative treatment with analgesic medication to invasive treatments by interventional endoscopy or surgery, differ between specialists, specialties and centres.

In 2017 the international evidence based HaPanEU guideline was published [3]. This guideline propagates a multidisciplinary step-up approach for the treatment of chronic pancreatitis pain. However, solid data that sup- 
port this approach are partly lacking. The first step of treatment in this guideline is conservative therapy, including lifestyle management (e.g., cessation of smoking), pain medication and dietary advice. When pain persists despite proper pain therapy, endoscopy is suggested to treat i.e. outflow problems of the pancreatic duct in the case of strictures and obstruction by stones. Sometimes as a last resort, surgical drainage and/or resection procedures are proposed in the case endoscopy fails. In the recent years increasing evidence tested the step-up approach, and multiple studies suggest the superiority of surgery compared to conservative and endoscopic measures [4-6]. This article describes the indications and different surgical procedures in chronic pancreatitis and puts focus on the timing of surgery in relation to other treatment modalities.

\section{Pain Mechanisms in Chronic Pancreatitis}

Traditionally, pathophysiological mechanisms on the origin of chronic pancreatitis pain were mainly focussed on structural abnormalities of the pancreas. Three mechanisms have been suggested to cause pain in chronic pancreatitis: (1) inflammation of the pancreas; (2) increased intrapancreatic pressure within the parenchyma and/or pancreatic duct causing tissue ischaemia, due to pancreatic duct strictures and/or stones; and (3) (late) pancreatic and extrapancreatic complications (i.e., pseudocysts, portal thrombosis, bile duct/duodenal strictures and peptic ulcers) [7-12]. However, these three mechanisms do not explain why there is sometimes a discrepancy between complaints and structural abnormalities of the pancreas; i.e., intense pain with hardly any morphological abnormalities of the pancreas. Rather than a single mechanism of pain, recent research favours a more complex interaction between structural and morphological changes of the pancreas, neurobiological mechanisms and structural abnormalities in the peripheral and central nervous system [13]. Peripheral and central sensitization of the nervous system together with alternative nociceptive pathways may explain why pain processing can change during disease progression and pain may persist after successful interventions $[14,15]$. Therefore, not only morphological changes should guide clinicians in their decision for any treatment, but also the source and character of pain should be considered for the success and timing of an invasive intervention.

\section{Step-Up Approach for the Treatment of Chronic Pancreatitis Pain}

\section{Medical Therapy}

Pain management in chronic pancreatitis is based on the approach of the World Health Organization [16]. Based on this approach, when pain control is not reached with non-opioids, weak opioids such as tramadol are advised, followed by strong opioids. Occasionally, S-ketamine or gabapentinoids can be added to this regime and have shown beneficial short-term results $[17,18]$. Longterm beneficial effects of opioids on chronic pancreatitis pain are not proven; still, $50 \%$ of chronic pancreatitis patients use opioids on a daily basis [19]. Interestingly, pain relief can be achieved in a large proportion of these patients by treating their morphological abnormalities by interventional endoscopy or surgery [3, 20-23]. Bearing in mind that the longer patients are treated with opioids, the greater the risk of opioid dependence and opioid-induced hyperalgesia, it seems better to use opioids as a bridge to invasive treatment when morphological abnormalities are present instead of definitive treatment $[3,24]$.

\section{Interventional Endoscopy}

Endoscopic interventions to treat chronic pancreatitis pain are mainly aimed at resolving obstruction of the pancreatic duct by dilation or stenting of strictures in the pancreatic and common bile duct or by pancreatic duct stone removal [25]. Technical success can be reliably achieved in appropriately selected patients (i.e., manageable stone size and disease predominantly in the pancreatic head). One of the largest series of 1,018 patients with painful obstructive chronic pancreatitis who were treated endoscopically, reported pain relief in $65 \%$ of patients after a mean follow-up of 5 years [20]. Interestingly, a study in 70 chronic pancreatitis patients treated by endoscopy showed short-term pain relief of $97 \%$, but 21 of the 70 (30\%) patients had a pain relapse within 1 year after treatment [26]. Extracorporeal shock wave lithotripsy (ESWL) and endoscopic stone extraction can be effective in patients with large intraductal stones $(>5 \mathrm{~mm})$. One randomized controlled trial in 55 patients, in which ESWL with and without endoscopic stone extraction was analysed, showed that pain relief after 2 years was comparable between both groups (55 vs. 62\%) [27].

\section{Surgical Treatment}

Pain is the main indication for surgery in the vast majority of chronic pancreatitis patients. Surgery in chronic pancreatitis can be technically demanding and carries a significant risk of postoperative morbidity but a low risk of mortality [28-30]. A series on surgical treatment in chronic pancreatitis shows excellent long-term results [30]. The optimal timing of surgery, however, continues to be a point of debate $[3,4]$. Whereas previously surgeons tried to hold off surgery until all medical and endoscopic options were exhausted, more recently others advocate early surgery because of its suggested superiority in treating pain.

Surgical procedures in chronic pancreatitis involve pancreatic parenchymal resection, pancreatic duct drainage or a combination of both (Fig. 1). The choice of op- 


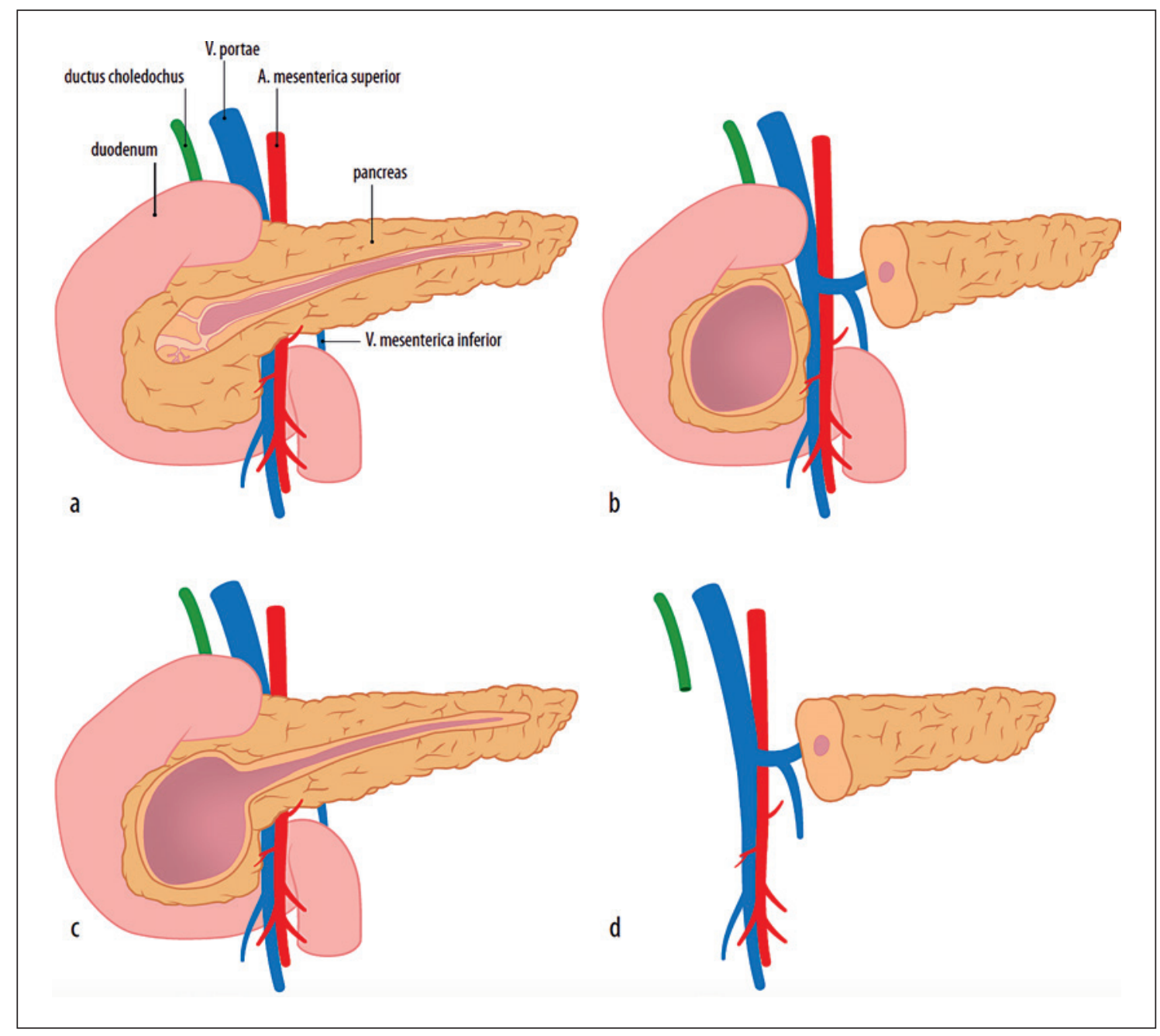

Fig. 1. Surgical treatment of chronic pancreatitis. a Lateral pancreaticojejunostomy. b Beger procedure. c Frey procedure. d Pancreaticoduodenectomy (picture used with permission from Nederlands Tijdschrift voor Geneeskunde) [65].

eration depends mainly on the morphological changes of the pancreas. Often seen are patients with changes in the pancreatic head demonstrating an inflammatory mass, sometimes considered to be the "pacemaker" of chronic pancreatitis [31]. Others have a more extensive and diffuse disease including the majority of the pancreatic duct with strictures and stones. Occasionally the disease seems limited to only the body or tail.

Two randomized controlled trials have been performed in patients with painful obstructive chronic pancreatitis comparing endoscopic with surgical interventions $[28,32]$. Both studies reported long-lasting superiority of the surgical approach for pain relief, quality of life and other end points. In the study of Díte et al. [32], 72 patients with painful chronic pancreatitis were randomized and after 5 years of follow-up 34\% of patients had complete and $52 \%$ partial pain relief after surgery, versus $15 \%$ complete pain absence and $46 \%$ partial pain relief after endoscopy. However, no ESWL was applied in this study [32]. In the study of Cahen et al. [28], 39 patients with painful chronic pancreatitis were randomized between surgery and endoscopy, and after 2 years of followup $75 \%$ pain relief after surgery was reported versus 32\% after endoscopy (including ESWL). Also, after 6 years of follow-up these results remained significant, with $80 \%$ pain relief in the surgery group versus $38 \%$ pain relief in the endoscopy group. In $53 \%$ of patients after surgery versus 25\% after endoscopy no pain was reported [33].

Based on the available evidence, surgery provides a superior outcome to interventional endoscopy overall, but there are clearly some patients who may benefit from the latter due to its less invasive approach [3]. Patients best suited to endoscopic intervention include those with stones or strictures confined to the head of the pancreas and where complete ductal clearance can be achieved. In current practice, a substantial part of chronic pancreatitis patients is offered interventional endoscopy first causing a delay in referral for surgery. 


\section{Chronic Pancreatitis with Large Duct Disease}

A dilated main pancreatic duct is defined by a size of at least $5 \mathrm{~mm}$ [3]. Ductal dilation may be diffuse along the pancreas or more located upstream from a single stricture. In many patients, stones may be present in the main or secondary duct(s).

\section{Partington-Rochelle or (Modified) Puestow}

Procedure - Lateral Pancreaticojejunostomy

The Partington-Rochelle procedure is the procedure of choice for main pancreatic duct dilation in the absence of an inflammatory mass and no biliary obstruction in the pancreatic head [34]. During this procedure the pancreatic head and duodenum are fully mobilized (Kocher's manoeuvre), and the anterior surface of the pancreas is fully exposed by accessing the omental bursa through splicing the gastrocolic ligament. The gastroduodenal artery is routinely identified and suture ligated at the superior and inferior border of the pancreas to prevent bleeding when the pancreas is opened. On the surface of the pancreas either the dilated pancreatic duct can be seen or palpated or can be accessed by aspiration through a fine needle or identified with intra-operative ultrasound. The duct is then incised longitudinally for the full length of the pancreas so that stones could be cleared and all strictures opened. A lateral pancreaticojejunostomy is created using a Roux-en-Y anastomosis.

Results of the Partington-Rochelle procedure are generally favourable. In well-selected patients (i.e., without an inflammatory mass) $70-80 \%$ durable pain relief is achieved during 5-10 years of follow-up [29, 35]. After a Partington-Rochelle procedure, morbidity is low, especially compared to other pancreatic procedures, and generally the endocrine and exocrine function is preserved because hardly any parenchyma is resected [35]. Failure of lateral pancreaticojejunostomy is described, most of the times this is in patients where inflammation of the pancreas (head) should have been resected or ongoing fibrosis of the peripancreatic tissue causes neuropathic pain [35].

\section{Chronic Pancreatitis with Enlarged Pancreatic Head}

Lateral pancreaticojejunostomy has limited applicability in patients in main duct dilatation who also have an inflammatory head mass $(>4 \mathrm{~cm})$ [3]. Multiple studies showed that isolated drainage procedures in patients with inflammatory changes of the head, body or tail result in poor long-term pain control and progression to exocrine insufficiency $[36,37]$.

For patients who have an isolated inflammatory mass of the pancreas without main duct dilatation, outcome appears to be better with a resection or a hybrid proce- dure where resection and drainage procedures are combined. The four most used procedures are: (1) pancreaticoduodenectomy (with or without pyloric preservation), or a duodenum-preserving procedure, (2) the Frey procedure, (3) the Berne procedure, and (4) the Beger procedure $[31,38-40]$.

\section{Pancreaticoduodenectomy}

The advantages of a pancreaticoduodenectomy over a duodenum-preserving procedure is that when there is a suspicion of a tumour in the pancreatic head an oncological radical procedure can be performed. Concomitant obstruction of the common bile duct or duodenum is also treated by this procedure. A disadvantage of the pancreatoduodenectomy is the resection of the duodenum which has beneficial effects on the hormonal axis in the gastrointestinal tract and leads to faster recovery of weight with a better glucose homeostasis [41].

\section{Frey Procedure}

The Frey procedure combines a duodenum-preserving head resection with drainage of the main pancreatic duct of the pancreatic body and tail.

In this procedure, the pancreatic head is not fully resected, but cored out until there is only a rim of pancreatic tissue left on the duodenum and portal vein. The main pancreatic duct is then drained longitudinally for its full length into the pancreatic tail. A lateral pancreaticojejunostomy is used to fully cover and drain the pancreas.

An advantage of the Frey procedure compared to pancreatic head resection is that it also can treat duct disease in the pancreatic remnant and that coring out the pancreatic head appears to be safer than a pancreatic head resection when portal hypertension or thrombosis is present. A disadvantage could be that a rim of pancreatic tissue of the pancreatic head with active disease is left in place.

\section{Berne Procedure}

In the presence of an inflammatory mass of the pancreatic head and in the absence of an enlarged pancreatic duct, the Berne procedure could be performed. The surgical approach and steps are similar to the Beger procedure. However, instead of a resection of the pancreatic head the head is cored out in a similar fashion as the Frey procedure, and no dissection of the portal and superior mesenteric vein is needed. No further drainage of the pancreatic duct is performed, and a pancreaticojejunostomy is made on the pancreatic head.

\section{Beger Procedure}

The duodenum-preserving pancreatic head resection was first described by Beger et al. [42] and developed to avoid some of the adverse sequelae of the pancreaticoduodenectomy. A pancreatic head resection is performed 
and only a small part of pancreatic tissue is left on the duodenum to preserve the duodenum. In this procedure the stomach and common bile duct are not divided. In $25 \%$ of the cases it is still necessary to perform a biliary anastomosis on the intrapancreatic part of the common bile duct [42]. A two-sided pancreaticojejunostomy is performed on the small part of pancreatic tissue on the duodenum and on the pancreas remnant.

Compared to the pancreaticoduodenectomy an advantage of the Beger procedure is that the duodenum is preserved and that only an anastomosis should be made on both sides of the pancreas. A disadvantage is that it can be a technically demanding operation with a technical difficult anastomosis.

Outcome of Surgery for Enlarged Pancreatic Head in Chronic Pancreatitis

Six randomized clinical trials have focussed on the comparison of the pancreaticoduodenectomy and duodenum-preserving operations such as the Frey and Beger procedures [41, 43-47]. In a meta-analysis of the first 4 trials all studies showed low morbidity and mortality with excellent perioperative outcomes [30]. Overall, no differences between the duodenum-preserving head resection and pancreaticoduodenectomy could be found. Longterm results of these trials did not show any differences between procedures for pain relief; all studies showed a long-term pain relief of around $80 \%$ after 7-15 years of follow-up and equal exocrine and endocrine function [30]. Additionally, all studies showed shorter operation times in the duodenum-preserving group and improved postoperative weight. It should be noted that some patients who were operated with a Beger or Frey procedure, compared to the pancreaticoduodenectomy, had more re-operations in the long term for duodenal or bile duct stenosis. A recently published German multicentre randomized controlled trial compared duodenum-preserving pancreatic head resection with partial pancreaticoduodenectomy in 250 patients with chronic pancreatitis and an inflammatory pancreatic head mass. Two years after surgery, pain scores and the mean quality of life had significantly improved in both groups, without significant differences between treatment groups [47].

In various studies, the Frey and Beger procedures were compared [41, 44-46]. Postoperative mortality was low $(<1 \%)$ for both procedures, and morbidity ranged between 19 and $32 \%$. In $75 \%$ of the patients, good pain relief was obtained in the short-term. After follow-up as long as 9 years, no significant differences were found in pain scores and endocrine and exocrine insufficiency. Comparable results were found in studies comparing the Beger and Berne procedure [48].

An international survey among surgeons showed that US surgeons tend to favour the pancreaticoduodenecto- my and European surgeons (in particular German surgeons) tend to favour the duodenum-preserving resections [49]. Differences in morphology (more often enlarged pancreatic head in Germany compared to the USA), anatomical complications and indications might explain the difference between the choice of surgery between countries.

In spite of the lack of data supporting the superiority of any given procedure, we believe that every procedure has some disease-specific advances. A pancreaticoduodenectomy should be performed when there are doubts about the presence of a pancreatic head tumour. Patients with a dominant pancreatic head mass, no enlarged pancreatic duct and no biliary obstruction are served best with a Berne or Beger procedure. When a pancreatic head mass is present with an enlarged pancreatic duct, a Frey procedure should be performed. In case of a concomitant biliary obstruction, a lateral hepaticojejunostomy can be created downstream on the same Roux loop as used for the pancreatic anastomosis.

\section{Chronic Pancreatitis with Small Duct Disease or Diffuse Sclerosis}

When chronic pancreatitis progresses, in many patients there will be no dominant focus of ductal obstruction or inflammatory mass. In these patients, the morphology of the disease is characterized by diffuse fibrosis of the pancreas with calcifications and atrophy of the parenchyma. Treating these patients is a major challenge, because a target for endoscopy or surgery is lacking. Total or near-total pancreatectomy could be performed in these cases but were often avoided in the past due to significant morbidity associated with endocrine (brittle diabetes) and exocrine insufficiency.

Since its introduction in 1977, around 1,000 total pancreatectomies with islet auto-transplant (TPIAT) have been described in the literature $[50,51]$. During TPIAT the complete pancreas is removed and the source of pain (in the majority of patients) is directly treated, while maintaining islet cell function by reimplanting the patient's own islet cells in the portal circulation [51]. In most expert centres, indications for TPIAT in chronic pancreatitis are (must have all): (1) chronic narcotic dependence, (2) impaired quality of life, (3) no reversible cause of chronic pancreatitis, (4) unresponsive to maximal medical, endoscopic and sometimes surgical therapy and (5) adequate islet cell function (non-diabetic). TPIAT is thought to be most effective in patients with small duct disease, hereditary pancreatitis and paediatric patients. Prior pancreatic surgery (i.e., Beger, Frey or pancreaticoduodenectomy) is in some centres a contra-indication for TPIAT because surgery significantly decreases islet yield. 
Effectiveness of TPIAT was evaluated in a single-centre study, and in 215 of 742 patients undergoing TPIAT sustained pain relief was observed in $82 \%$ after 10 years and $90 \%$ after 15 years, with $50 \%$ partial or full islet graft function [51].

\section{Surgical Strategy in Complications of Chronic Pancreatitis}

During the course of chronic pancreatitis about a third of patients will develop complications leading to considerable morbidity. Modern imaging facilitates tailored treatment, either surgery, interventional radiology or endoscopy.

Pancreatic fluid collections and pseudocysts are often present in chronic pancreatitis and differ from those seen in necrotizing pancreatitis because they hardly contain any necrotic material, have a higher incidence of direct communication with the pancreatic duct and are less likely to resolve spontaneously [52]. Asymptomatic collections/cysts, in general, can be safely observed. Symptomatic collections/cysts will require drainage. High-quality evidence is lacking, but accumulating evidence has shown good results of endoscopic transduodenal and transgastric drainage $[3,25,53,54]$. Pancreatic ascites and pleural effusions can occur when there is a disruption or a leak from a pancreatic fluid collection or pseudocyst. The natural course of pancreatic ascites varies, but in some patients, it will resolve spontaneously or after conservative measures like parenteral or nasojejunal feeding. When unsuccessful, endoscopic intervention with papillotomy and/or stenting of the pancreatic duct have shown beneficial results $[3,25,55]$.

Bile duct obstruction is often seen in advanced stages of chronic pancreatitis and is usually directly related to an inflammatory mass in the pancreatic head. Symptomatic obstructions should be treated. Stenting of the bile duct is performed most often, but surgical drainage/bypass remains the most definitive long-term solution [3,25]. Surgery should be considered in all patients who are fit for surgery and those without portal hypertension. The type of surgery depends on other associated morphological abnormalities. When an enlarged pancreatic head and/or duodenal stenosis is present, a pancreaticoduodenectomy seems most suitable. When an enlarged pancreatic duct is present, a Frey procedure with hepaticojejunostomy can be considered.

Duodenal obstruction can be stented temporarily by endoscopy. However, surgery should provide the definitive solution. The type of surgery depends on the morphological abnormalities, ranging from kocherisation for a fibrotic band surrounding the duodenum, to a bypass operation i.e. gastroenterostomy or a pancreaticoduode- nectomy when an inflammatory mass in the head of the pancreas is present $[3,25]$.

Haemorrhage associated with chronic pancreatitis can be due to portal hypertension with gastric varices, peptic ulcer disease and aneurysms of the vessels surrounding the pancreas. Depending on the cause, most cases can be managed endoscopically or by interventional radiology. Surgery should be the last resort and is aimed at controlling the bleeding [56].

\section{Timing of Surgery in Chronic Pancreatitis}

In the current literature and guidelines for painful obstructive chronic pancreatitis, inconsistency is found regarding the timing and choice for surgery or endoscopy first $[3,23,25]$. Recently, multiple studies have suggested that early surgery is superior in providing pain relief and improvement of quality of life, compared to the step-up approach in which medical therapy is followed by endoscopy and finally surgery [4-6]. Delaying invasive treatment such as surgery was negatively associated in an observational study, with the duration of pre-operative opioid use, multiple endoscopic interventions and the duration of chronic pancreatitis [4]. In general, it has been shown for multiple disorders, including chronic pancreatitis, that delayed interventions for chronic pain lead to ongoing opioid use, repeated episodes of intense pain, which are all directly related to poor pain outcome and the development of difficult to control chronic pain syndromes [13]. To provide answers to the optimal timing of surgery in chronic pancreatitis, the Dutch Pancreatitis Study Group started the ESCAPE trial [57] Patients with painful obstructive chronic pancreatitis were included in an early phase of their disease, prior to any interventions and with a maximum of 2 months of opioid use. Patients were randomized to either surgery within 6 weeks after randomization or the current step-up approach including endoscopy. The Izbicki pain score, a validated pain score specific for chronic pancreatitis, was used as a primary outcome $[28,45,58]$. The study is not yet published, but an abstract confirming the superiority of early surgical intervention was presented at the United European Gastroenterology Week 2018.

\section{Neuropathic Pain}

Failure to treat pain after invasive procedures in chronic pancreatitis is not uncommon. A plausible explanation for these failures can be due to changes in pain processing $[13,23,59]$. Nociceptive input from the pancreas to the central nervous system can be altered by structural chang- 
es of the nerves innervating the pancreas resulting in hyperalgesia. Ongoing pain may induce peripheral sensitization (increased excitability) which will increase the nociceptive drive to the central nervous system resulting in an increased reaction of pain-transmitting neurons (increase in pain). This process may result in structural changes of the brain which makes patients vulnerable to a complex pain syndrome where nociceptive drive is not only located in the pancreas, but also in the peripheral and central nervous system.

In these categories of patients, it is very difficult to resolve pain by surgery or endoscopy. Neuropathic pain medication such as pregabalin and S-ketamine have shown some short-term beneficial results $[17,18]$. A randomized controlled trial with S-ketamine is currently ongoing [60]. Neuro-ablative procedures such as (endoscopic) celiac plexus blockade and bilateral thoracoscopic splanchnicectomy were performed often in the past. Despite short-term benefits, long-term benefits were often absent; therefore, these procedures are only indicated in selected cases [61-63].

\section{Future Perspectives}

Patient selection for invasive procedures and timing of procedures seems to be crucial in the success of treatments in chronic pancreatitis. Future research should aim at unravelling the full complexity of pain in chronic pancreatitis so we could better define different patient subgroups (continuous vs. recurrent pain patterns) and better predict the success of interventions aimed to treat pain. Several prospective cohorts of patients are current- ly focussing on pain characteristics, and these will result in a better understanding of the aspects of pain that are most amenable to treatment [64].

\section{Conclusion}

Based on recent high-quality evidence, (early) surgery is the most effective treatment for painful obstructive chronic pancreatitis. Interventional endoscopy still has an important role with good success rates, particularly in chronic pancreatitis patients with abnormalities confined to the head of the pancreas and when good ductal clearance can be achieved. The preliminary results of the ESCAPE trial showed that early surgery outperforms conservative treatment and endoscopy. When these data are confirmed in the final publication, this may have significant implications for daily clinical practice. This would mean that early in the disease course chronic pancreatitis patients need to be discussed in multidisciplinary groups in expert centres and early surgery needs to be considered. If the present step-up approach of conservative treatment and endoscopy is followed, one should bear in mind not to miss an early window of opportunity to operate on surgical treatable disease in chronic pancreatitis. Future research should focus on the many aspects of pain in chronic pancreatitis and how this is influenced by our interventions to improve patient selection for invasive treatment.

\section{Disclosure Statement}

The authors declare no conflicts of interest.

\section{References}

1 Lankisch PG, Breuer N, Bruns A, Weber-Dany B, Lowenfels AB, Maisonneuve P. Natural history of acute pancreatitis: a long-term population-based study. Am J Gastroenterol. 2009 Nov;104(11):2797-805.

2 Ammann RW, Akovbiantz A, Largiader F, Schueler G. Course and outcome of chronic pancreatitis. Longitudinal study of a mixed medical-surgical series of 245 patients. Gastroenterology. 1984 May;86(5 Pt 1):820-8.

3 Löhr JM, Dominguez-Munoz E, Rosendahl J, Besselink M, Mayerle J, Lerch MM, et al.; HaPanEU/UEG Working Group. United European Gastroenterology evidence-based guidelines for the diagnosis and therapy of chronic pancreatitis (HaPanEU). United European Gastroenterol J. 2017 Mar;5(2):15399.

4 Ahmed Ali U, Nieuwenhuijs VB, van Eijck $\mathrm{CH}$, Gooszen HG, van Dam RM, Busch OR, et al.; Dutch Pancreatitis Study Group. Clinical outcome in relation to timing of surgery in chronic pancreatitis: a nomogram to predict pain relief. Arch Surg. 2012 Oct;147(10):92532

5 Ke N, Jia D, Huang W, Nunes QM, Windsor JA, Liu X, et al. Earlier surgery improves outcomes from painful chronic pancreatitis. Medicine (Baltimore). 2018 May; 97(19):e0651.

6 Yang CJ, Bliss LA, Schapira EF, Freedman SD, Ng SC, Windsor JA, et al. Systematic review of early surgery for chronic pancreatitis: impact on pain, pancreatic function, and re-intervention. J Gastrointest Surg. 2014 Oct; 18(10):1863-9.

7 Andrén-Sandberg A, Dervenis C. Pancreatic pseudocysts in the 21st century. Part I: classification, pathophysiology, anatomic considerations and treatment. JOP. 2004 Jan;5(1): 8-24.

8 Abdallah AA, Krige JE, Bornman PC. Biliary tract obstruction in chronic pancreatitis. HPB (Oxford). 2007;9(6):421-8.
9 Vijungco JD, Prinz RA. Management of biliary and duodenal complications of chronic pancreatitis. World J Surg. 2003 Nov;27(11): 1258-70.

10 Barreto SG, Saccone GT. Pancreatic nociception - revisiting the physiology and pathophysiology. Pancreatology. 2012;12: 104-12.

11 Demir IE, Tieftrunk E, Maak M, Friess H, Ceyhan GO. Pain mechanisms in chronic pancreatitis: of a master and his fire. Langenbecks Arch Surg. 2011 Feb;396(2):151-60.

12 Poulsen JL, Olesen SS, Malver LP, Frøkjær JB, Drewes AM. Pain and chronic pancreatitis: a complex interplay of multiple mechanisms. World J Gastroenterol. 2013 Nov; 19(42): 7282-91.

13 Bouwense SA, de Vries M, Schreuder LT, Olesen SS, Frøkjær JB, Drewes AM, et al. Systematic mechanism-orientated approach to chronic pancreatitis pain. World J Gastroenterol. 2015 Jan;21(1):47-59. 
14 Bouwense SA, Ali UA, ten Broek RP, et al. Pain outcome after pancreatic surgery for pain of chronic pancreatitis: relation to altered central pain processing. Pancreas. 2012; 41:1350.

15 Bouwense SA, Olesen SS, Drewes AM, Frøkjær JB, van Goor H, Wilder-Smith $\mathrm{OH}$. Is altered central pain processing related to disease stage in chronic pancreatitis patients with pain? An exploratory study. PLoS One. 2013;8(2):e55460.

16 Jadad AR, Browman GP. The WHO analgesic ladder for cancer pain management. Stepping up the quality of its evaluation. JAMA. 1995 Dec;274(23):1870-3.

17 Olesen SS, Bouwense SA, Wilder-Smith $\mathrm{OH}$, van Goor H, Drewes AM. Pregabalin reduces pain in patients with chronic pancreatitis in a randomized, controlled trial. Gastroenterology. 2011 Aug;141(2):536-43.

18 Bouwense SA, Buscher HC, van Goor $\mathrm{H}$ Wilder-Smith OH. S-ketamine modulates hyperalgesia in patients with chronic pancreatitis pain. Reg Anesth Pain Med. 2011 May-Jun; 36(3):303-7.

19 Mullady DK, Yadav D, Amann ST, O’Connell MR, Barmada MM, Elta GH, et al.; NAPS2 Consortium. Type of pain, pain-associated complications, quality of life, disability and resource utilisation in chronic pancreatitis: a prospective cohort study. Gut. 2011 Jan;60(1): 77-84.

20 Rösch T, Daniel S, Scholz M, Huibregtse K, Smits M, Schneider T, et al.; European Society of Gastrointestinal Endoscopy Research Group. Endoscopic treatment of chronic pancreatitis: a multicenter study of 1000 patients with long-term follow-up. Endoscopy. 2002 Oct;34(10):765-71.

21 Ammann RW, Muench R, Otto R, Buehler H, Freiburghaus AU, Siegenthaler W. Evolution and regression of pancreatic calcification in chronic pancreatitis. A prospective long-term study of 107 patients. Gastroenterology. 1988 Oct;95(4):1018-28.

22 Maydeo A, Soehendra N, Reddy N, Bhandari $\mathrm{S}$. Endotherapy for chronic pancreatitis with intracanalar stones. Endoscopy. 2007 Jul; 39(7):653-8.

23 Drewes AM, Bouwense SA, Campbell CM, Ceyhan GO, Delhaye M, Demir IE, et al; Working group for the International (IAPAPA-JPS-EPC) Consensus Guidelines for Chronic Pancreatitis. Guidelines for the understanding and management of pain in chronic pancreatitis. Pancreatology. 2017 Sep-Oct;17(5):720-31.

24 Simonnet G, Rivat C. Opioid-induced hyperalgesia: abnormal or normal pain? Neuroreport. 2003 Jan;14(1):1-7.

25 Dumonceau JM, Delhaye M, Tringali A, Arvanitakis M, Sanchez-Yague A, Vaysse T, et al. Endoscopic treatment of chronic pancreatitis: European Society of Gastrointestinal Endoscopy (ESGE) Guideline - Updated August 2018. Endoscopy. 2019 Feb;51(2):179-93.

26 Tadenuma H, Ishihara T, Yamaguchi T, et al Long-term results of extracorporeal shockwave lithotripsy and endoscopic therapy for pancreatic stones. Clin Gastroenterol Hepatol. $2005 ; 3: 1128-35$.
27 Dumonceau JM, Costamagna G, Tringali A, Vahedi K, Delhaye M, Hittelet A, et al. Treatment for painful calcified chronic pancreatitis: extracorporeal shock wave lithotripsy versus endoscopic treatment: a randomised controlled trial. Gut. 2007 Apr;56(4):545-52.

28 Cahen DL, Gouma DJ, Nio Y, Rauws EA, Boermeester MA, Busch OR, et al. Endoscopic versus surgical drainage of the pancreatic duct in chronic pancreatitis. N Engl J Med. 2007 Feb;356(7):676-84.

29 van der Gaag NA, van Gulik TM, Busch OR, Sprangers MA, Bruno MJ, Zevenbergen C, et al. Functional and medical outcomes after tailored surgery for pain due to chronic pancreatitis. Ann Surg. 2012 Apr;255(4):763-70.

30 Diener MK, Rahbari NN, Fischer L, Antes G, Büchler MW, Seiler CM. Duodenum-preserving pancreatic head resection versus pancreatoduodenectomy for surgical treatment of chronic pancreatitis: a systematic review and meta-analysis. Ann Surg. 2008 Jun; 247(6):950-61

31 Beger HG, Büchler M. Duodenum-preserving resection of the head of the pancreas in chronic pancreatitis with inflammatory mass in the head. World J Surg. 1990 Jan-Feb;14(1):83-7.

32 Díte P, Ruzicka M, Zboril V, Novotný I. A prospective, randomized trial comparing endoscopic and surgical therapy for chronic pancreatitis. Endoscopy. 2003 Jul;35(7):5538.

33 Cahen DL, Gouma DJ, Laramée P, Nio Y, Rauws EA, Boermeester MA, et al. Long-term outcomes of endoscopic vs surgical drainage of the pancreatic duct in patients with chronic pancreatitis. Gastroenterology. 2011 Nov; 141(5):1690-5.

34 Partington PF, Rochelle RE. Modified Puestow procedure for retrograde drainage of the pancreatic duct. Ann Surg. 1960 Dec; 152(6):1037-43.

35 van der Gaag NA, Gouma DJ, van Gulik TM, Busch OR, Boermeester MA. Review article: surgical management of chronic pancreatitis. Aliment Pharmacol Ther. 2007 Dec;26 Suppl 2:221-32.

36 Prinz RA, Greenlee HB. Pancreatic duct drainage in 100 patients with chronic pancreatitis. Ann Surg. 1981 Sep;194(3):313-20.

37 Prinz RA, Greenlee HB. Pancreatic duct drainage in chronic pancreatitis. Hepatogastroenterology. 1990 Jun;37(3):295-300.

38 Gloor B, Friess H, Uhl W, Büchler MW. A modified technique of the Beger and Frey procedure in patients with chronic pancreatitis. Dig Surg. 2001;18(1):21-5.

39 Whipple AO, Parsons WB, Mullins CR. Treatment of Carcinoma of the Ampulla of Vater. Ann Surg. 1935 Oct;102(4):763-79.

40 Frey CF, Smith GJ. Description and rationale of a new operation for chronic pancreatitis. Pancreas. 1987;2(6):701-7.

41 Müller MW, Friess H, Martin DJ, Hinz U, Dahmen R, Büchler MW. Long-term followup of a randomized clinical trial comparing Beger with pylorus-preserving Whipple procedure for chronic pancreatitis. Br J Surg. 2008 Mar;95(3):350-6

42 Beger HG, Schlosser W, Friess HM, Büchler MW. Duodenum-preserving head resection in chronic pancreatitis changes the natural course of the disease: a single-center 26-year experience. Ann Surg. 1999 Oct;230(4):512-9.

43 Farkas G, Leindler L, Daróczi M, Farkas G Jr. Prospective randomised comparison of organ-preserving pancreatic head resection with pylorus-preserving pancreaticoduodenectomy. Langenbecks Arch Surg. 2006 Aug; 391(4):338-42

44 Keck T, Adam U, Makowiec F, Riediger H, Wellner U, Tittelbach-Helmrich $\mathrm{D}$, et al. Short- and long-term results of duodenum preservation versus resection for the management of chronic pancreatitis: a prospective, randomized study. Surgery. 2012 Sep;152(3 Suppl 1):S95-102

45 Izbicki JR, Bloechle C, Broering DC, Knoefel WT, Kuechler T, Broelsch CE. Extended drainage versus resection in surgery for chronic pancreatitis: a prospective randomized trial comparing the longitudinal pancreaticojejunostomy combined with local pancreatic head excision with the pylorus-preserving pancreatoduodenectomy. Ann Surg. 1998 Dec;228(6):771-9.

46 Klempa I, Spatny M, Menzel J, Baca I, Nustede R, Stöckmann F, et al. [Pancreatic function and quality of life after resection of the head of the pancreas in chronic pancreatitis. A prospective, randomized comparative study after duodenum preserving resection of the head of the pancreas versus Whipple's operation]. Chirurg. 1995 Apr;66(4):350-9.

47 Diener MK, Hüttner FJ, Kieser M, Knebel P, Dörr-Harim C, Distler M, et al; ChroPac Trial Group. Partial pancreatoduodenectomy versus duodenum-preserving pancreatic head resection in chronic pancreatitis: the multicentre, randomised, controlled, doubleblind ChroPac trial. Lancet. 2017 Sep; 390(10099):1027-37.

48 Köninger J, Seiler CM, Sauerland S, Wente MN, Reidel MA, Müller MW, et al. Duodenum-preserving pancreatic head resection-a randomized controlled trial comparing the original Beger procedure with the Berne modification (ISRCTN No. 50638764). Surgery. 2008 Apr;143(4):490-8

49 Varghese TK, Bell RH, Jr. Duodenum-preserving head resection for chronic pancreatitis: an institutional experience and national survey of usage. Surgery 2007;142:588-93; discussion 93 e1-3.

50 Bellin MD, Freeman ML, Schwarzenberg SJ, et al. Quality of life improves for pediatric patients after total pancreatectomy and islet autotransplant for chronic pancreatitis. Clin Gastroenterol Hepatol. 2011;9:793-9.

51 Bellin MD, Beilman GJ, Sutherland DE, Ali H, Petersen A, Mongin S, et al. How Durable Is Total Pancreatectomy and Intraportal Islet Cell Transplantation for Treatment of Chronic Pancreatitis? J Am Coll Surg. 2019 Jan; 228(4):S1072-7515(19)30016-X.

52 Banks PA, Bollen TL, Dervenis C, Gooszen HG, Johnson CD, Sarr MG, et al.; Acute Pancreatitis Classification Working Group. Classification of acute pancreatitis-2012: revision of the Atlanta classification and definitions by international consensus. Gut. 2013 Jan;62(1):102-11 
53 Varadarajulu S, Christein JD, Tamhane A, Drelichman ER, Wilcox CM. Prospective randomized trial comparing EUS and EGD for transmural drainage of pancreatic pseudocysts (with videos). Gastrointest Endosc. 2008 Dec;68(6):1102-11

54 Park DH, Lee SS, Moon SH, Choi SY, Jung SW, Seo DW, et al. Endoscopic ultrasoundguided versus conventional transmural drainage for pancreatic pseudocysts: a prospective randomized trial. Endoscopy. 2009 Oct; 41(10):842-8.

55 Larsen M, Kozarek R. Management of pancreatic ductal leaks and fistulae. J Gastroenterol Hepatol. 2014;29(7):1360-70.

56 Chiang KC, Chen TH, Hsu JT. Management of chronic pancreatitis complicated with a bleeding pseudoaneurysm. World J Gastroenterol. 2014 Nov;20(43):16132-7.

57 Ahmed Ali U, Issa Y, Bruno MJ, van Goor H, van Santvoort H, Busch OR, et al.; Dutch Pancreatitis Study Group. Early surgery versus optimal current step-up practice for chronic pancreatitis (ESCAPE): design and rationale of a randomized trial. BMC Gastroenterol. 2013 Mar;13(1):49.
58 Bloechle C, Izbicki JR, Knoefel WT, Kuechler T, Broelsch CE. Quality of life in chronic pancreatitis-results after duodenum-preserving resection of the head of the pancreas. Pancreas. $1995 \mathrm{Jul} ; 11(1): 77-85$.

59 Bouwense SA, Ahmed Ali U, ten Broek RP, Issa $\mathrm{Y}$, van Eijck $\mathrm{CH}$, Wilder-Smith $\mathrm{OH}$, et al. Altered central pain processing after pancreatic surgery for chronic pancreatitis. Br J Surg. 2013 Dec;100(13): 1797-804

60 Juel J, Olesen SS, Olesen AE, Poulsen JL, Dahan $\mathrm{A}$, Wilder-Smith $\mathrm{O}$, et al. Study protocol for a randomised, double-blinded, placebocontrolled, clinical trial of S-ketamine for pain treatment in patients with chronic pancreatitis (RESET trial). BMJ Open. 2015 Mar; 5(3):e007087.

61 Buscher HC, Schipper EE, Wilder-Smith OH, Jansen JB, van Goor H. Limited effect of thoracoscopic splanchnicectomy in the treatment of severe chronic pancreatitis pain: a prospective long-term analysis of 75 cases. Surgery. 2008 Jun;143(6):715-22.
62 Baghdadi S, Abbas MH, Albouz F, Ammori BJ. Systematic review of the role of thoracoscopic splanchnicectomy in palliating the pain of patients with chronic pancreatitis. Surg Endosc. 2008 Mar;22(3):580-8.

63 Issa Y, Ali UA, Bouwense SA, van Santvoort $\mathrm{HC}$, van Goor H. Preoperative opioid use and the outcome of thoracoscopic splanchnicectomy in chronic pancreatitis: a systematic review. Surg Endosc. 2014 Feb;28(2): 405-12.

64 Olesen SS, Krauss T, Demir IE, Wilder-Smith $\mathrm{OH}$, Ceyhan GO, Pasricha PJ, et al. Towards a neurobiological understanding of pain in chronic pancreatitis: mechanisms and implications for treatment. Pain Rep. 2017 Oct; 2(6):e625.

65 Kempeneers MA, Besselink MG, Issa Y, van Hooft JE, van Goor H, Bruno MJ, et al. [Multidisciplinary treatment of chronic pancreatitis: an overview of current step-up approach and new options]. Ned Tijdschr Geneeskd. 2017;161:D1454. Dutch. 